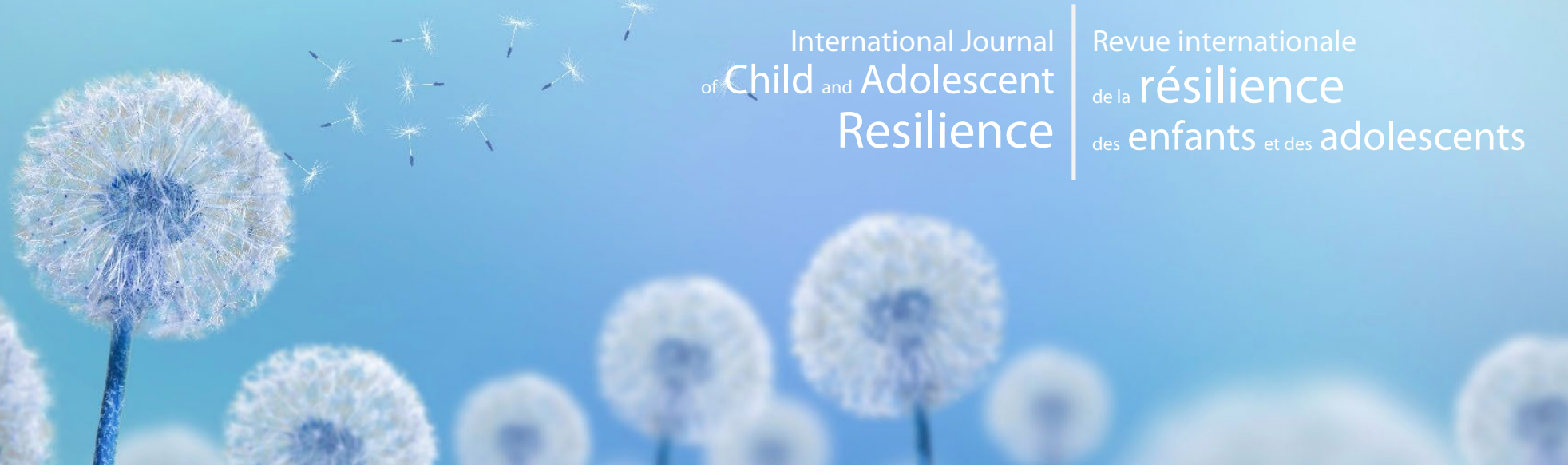

\title{
"A journey back to my wholeness": A qualitative metasynthesis on the relational and sexual recovery process of child sexual abuse survivors
}

Roxanne GUYON ${ }^{1}$, Mylène FERNET ${ }^{1}$, and Natacha GODBOUT ${ }^{1}$

1 Département de sexologie, Université du Québec à Montréal

Corresponding Author: Mylène Fernet, Département de sexologie, Université du Québec à Montréal, C.P. 8888, succursale CentreVille, Montréal, Québec, Canada H3C 3P8.

Email: fernet.mylene@uqam.ca.

\section{Abstract}

Objective: This study aims to document the relational and sexual recovery process of child sexual abuse (CSA) survivors.

Method: Using the framework-based synthesis approach (Dixon-Woods, 2011), a metasynthesis was conducted on qualitative peer-reviewed studies published between 2004 and 2019, focusing on the recovery from relational and sexual outcomes related to CSA experiences. Criteria of inclusion: 1) included self-identified men or women who had sustained sexual abuse in childhood; 2) focused on CSA related relational or sexual outcomes and recovery processes; 3) included a qualitative component incorporating interviews or focus groups; 4) were carried out in Western countries. According to these criteria, a sample of eight articles was constituted. A direct content analysis was performed using The Drive to Move Forward Framework (Ochocka et al., 2005).

Results: Findings yielded three main categories that illustrate the relational and sexual recovery process of CSA survivors: 1) The Drive to Move Forward after CSA; 2) Positive Strategies Mobilized to Recover from Relational and Sexual Issues Left by CSA and; 3) Social Circumstances that Facilitate or Hinder the Relational and Sexual Recovery Process.

Conclusion: Although their relational and sexual recovery process may involve setbacks, and that they may be confronted with impeding social circumstances, survivors mobilize strategies and social resources to help them move forward after CSA.

Implication: In order to help CSA survivors in achieving a satisfying relational and sexual life, providers should adopt a personalized approach that respects their process of relational and sexual recovery and adopt an ecological perspective to better understand the factors that can modulate this process.

Keywords: Qualitative metasynthesis, child sexual abuse, recovery, sexuality, relationships, gender. 


\footnotetext{
"A journey back to my wholeness": A qualitative metasynthesis on the relational

and sexual recovery process of child sexual abuse survivors
}

\section{Introduction}

Child sexual abuse (CSA) is considered as an alarming public health issue (Kendall-Tackett, 2012) causing a wide range of impacts in children, which can persist or even be exacerbated in adulthood (Trickett et al., 2011). A 30year longitudinal study reported several outcomes in adult survivors of CSA, such as increased risks of PTSD symptoms, major depression and anxiety disorder, decreased self-esteem and life satisfaction, as well as suicidal ideation or suicide attempt, and alcohol or drug dependence (Fergusson et al., 2013). Regarding their sexuality, CSA survivors are more prone to experiment risky sexual behaviors (Homma et al., 2012), flashbacks during sexual intercourses (Carreiro et al., 2016), sexual avoidance (O'Leary et al., 2017) or compulsivity (Aaron, 2012; Vaillancourt-Morel et al., 2015) and may hold a more negative sexual self-concept (Guyon et al., 2020). They are more likely to use sexuality as a strategy to cope with negative feelings (Lemieux \& Byers, 2008) and to sexualize their interpersonal relationships to meet their emotional needs (Guyon et al., 2019). Survivors are also more inclined to be distrustful in their intimate relationships (Alaggia \& Millington, 2008) and to report difficulties with intimacy and proximity (Crete \& Singh, 2015; Godbout et al., 2013). Additionally, survivors show lower levels of relationship satisfaction (Berthelot et al., 2014), which can lead to difficulties in building lasting healthy relationships.

Multiple difficulties and symptoms related to CSA have led researchers to study how survivors adapt to these adverse life experiences. Recently, the concepts of resilience, posttraumatic growth, healing, and recovery have received more attention in the scientific body of knowledge. Recent qualitative studies as well as metasynthesis (Draucker et al., 2009; Jeong \& Cha, 2019) have documented the general recovery or healing processes used by survivors to cope with CSA and its multiple consequences. Healing and recovery are similar concepts that refer to a process over time, resulting in positive changes from adverse life experiences, but which may comprise episodes of stepping backwards (Calhoun et al., 2000). Even if there is a lack of consistency in defining and measuring this concept, resilience has been conceptualized in several recent studies as a dynamic process involving an interaction between several protective factors or resources available that help individuals to overcome adversity (i.e., personal, social and societal; Kolar, 2011; Ungar, 2012). Posttraumatic growth relies on the positive psychological changes experienced by resilient individuals following these events (Calhoun et al., 2010). A qualitative study documenting posttraumatic growth in CSA survivors shows that survivors may adopt positive coping behaviors and develop inner strengths to face CSA experiences and to achieve psychological well-being (Walker-Williams et al., 2013). A recent systematic review of 37 studies found several resilience factors fostering CSA survivors' adaptive functioning. The most reported protective factors were related to personal (e.g., emotional and interpersonal competences, optimism) and environmental components (e.g., education, social support; Domhardt et al., 2015). To explain the healing process of survivors, Draucker and colleagues (2011) proposed an integrative four-stages model: 1) struggling to find the meaning of CSA; 2) figuring out the meaning of CSA; 3 ) fighting against the difficulties lingering from CSA and; 4) becoming the owner of one's life. Besides supportive relationships, internal characteristics and turning points have also been reported as key factors in the process of healing from CSA experiences (Arias \& Johnson, 2013). Several studies that have documented the recovery processes from CSA evoked internal (e.g., personal insights, spirituality) and external (e.g., influential relationships) factors, as well as significant events (e.g., CSA disclosure or denunciation, giving birth), which are often reported as "turning points" (Banyard \& Williams, 2007; Easton et al., 2015).

Although a significant number of qualitative studies of CSA survivors have been conducted in recent years, many of these studies have identified recovery processes related to CSA experiences and its perceived consequences without specifically documenting the relational and sexual components of such processes. Yet, CSA is an interpersonal and sexual trauma in itself (i.e., it involves unwanted sexual acts mostly committed by a loved or trusted figure; Wager, 2013). This underlines the relevance to dwell on these specific components when investigating the recovery process of survivors. The processes depicted in previous metasynthesis on CSA recovery focused on internal mechanisms or changes within survivors themselves, whereas recovery processes seem to be also influenced by social mechanisms (Choate, 2012). It seems relevant to explore both individual and social factors that characterize the recovery process of CSA survivors facing relational and sexual challenges. A synthesis of qualitative data would offer an integrative portrait of this fragmented piece of literature and help identify the remaining gaps. Thus, through a metasynthesis of qualitative studies, this study aims to document the recovery process that CSA survivors will go through within their intimate relationships and sexuality, while incorporating social factors that may influence this process. 


\section{"A journey back to my wholeness": A qualitative metasynthesis on the relational and sexual recovery process of child sexual abuse survivors}

\section{Method}

\section{Study design}

A metasynthesis based on a framework synthesis approach (Dixon-Woods, 2011) was conducted. This method uses an a priori framework to synthetize qualitative findings chosen in regard of its theoretical relevance. This method is particularly useful to facilitate a rigorous analysis of the large amount of data by structuring the findings (DixonWoods, 2011) and to provide support for or to extend conceptually an existing theoretical framework (Elo \& Kyngäs, 2008). Since there are already many qualitative studies on the recovery processes of individuals who have experienced events of adversity, it is relevant to consider how an existing framework can be applied to CSA survivors regarding their relational and sexual difficulties. The framework used can then be improved and adapted as the analyses proceed (Dixon-Woods, 2011)

\section{Procedure and sample}

A review of qualitative peer-reviewed studies published in English between 2004 and May 2019 has been conducted to document the recovering process of adult survivors facing relational and sexual issues due to CSA experiences. Four databases (PsycINFO, Pubmed, SAGE Journals, and Gender Studies Database) were screened using a combination of the following search terms: resilience, recovery, healing, thriving, posttraumatic growth, positive adaptation, positive sexuality, child sexual abuse, sexual abuse, qualitative, and mixed methods. Studies were included according to five criteria: 1) they included self-identified men or women who had sustained sexual abuse in childhood; 2) they focused on CSA related relational or sexual outcomes and recovery processes; 3 ) they included a qualitative component incorporating interviews or focus groups; 4) they were carried out in Western countries. A total of 72 articles that met the five inclusion criteria were found. After verification, 46 duplicates were removed. Then, researchers reviewed the 26 potential articles. Among these, 13 articles were excluded because they did not include relational or sexual components (e.g., relational or sexual issues, coping with relational or sexual issues) as a part of their results; however, studies that partly addressed relational or sexual components were included. Two studies with results focusing on the effects of programs or treatments were excluded, as well as one study that targeted other forms of sexual violence in childhood (e.g., sex trafficking). Two studies were excluded because of their samples: one composed of children and one composed of adult survivors of complex trauma who did not all experienced CSA. Finally, although it did not explicitly evoke the terms resilience, recovery, healing or posttraumatic growth within its results, one study that addressed positive sexual self-schemas in women was included since these components are linked. The process of retrieving and screening articles is illustrated in Figure 1.

Figure 1. Flowchart illustrating the process of retrieving and screening articles

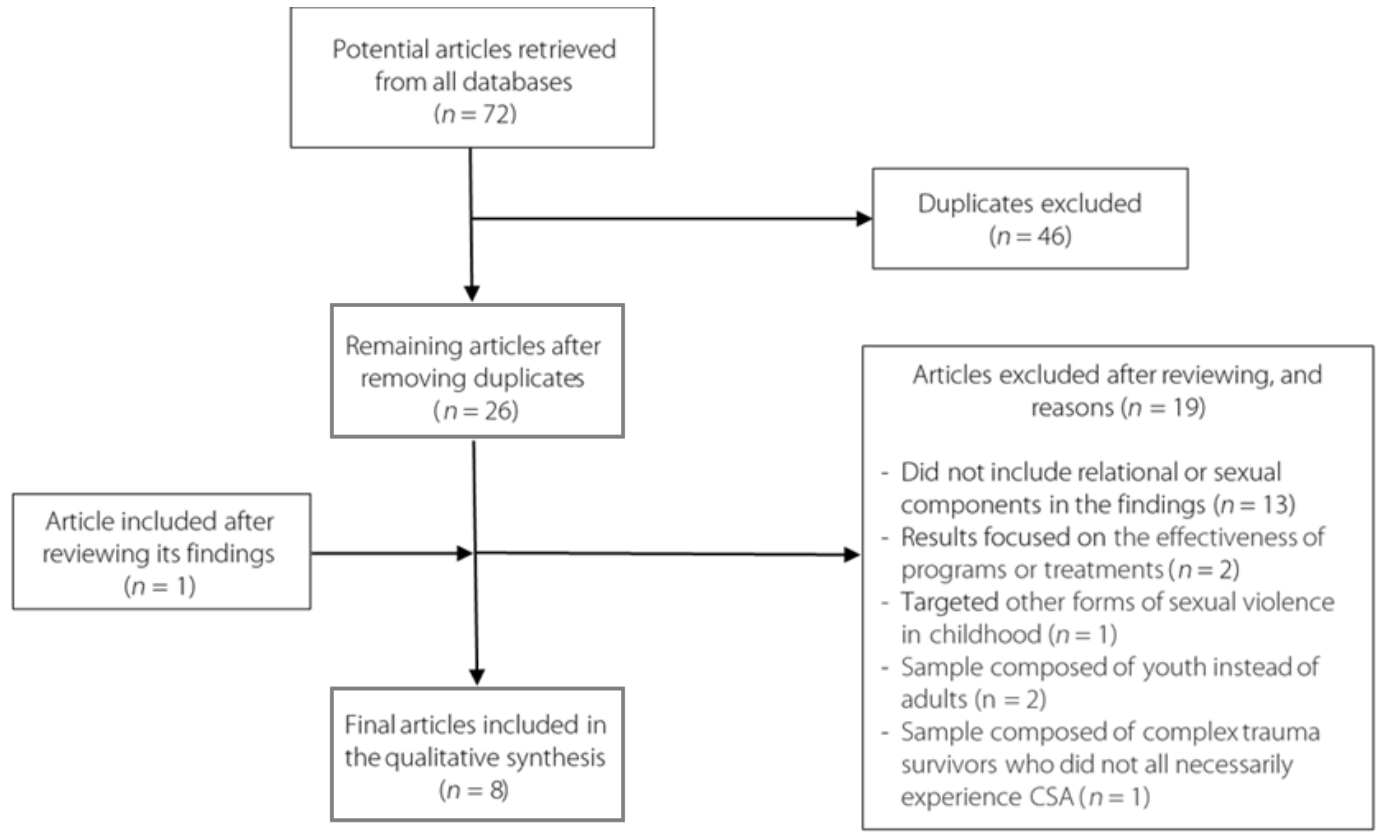




\section{"A journey back to my wholeness": A qualitative metasynthesis on the relational and sexual recovery process of child sexual abuse survivors}

A total of eight articles that met the inclusion criteria were analyzed. A summary of the designs used in each study along with the number and characteristics of participants, CSA criteria, approach to data analyses, and quality scores are presented in Table 1. Studies were mostly conducted in the United States and included survivors of severe CSA from various ethnic backgrounds aged between 18 to 62 years old. Four studies included exclusively female survivors while two included exclusively males. One included both male and female survivors and one study included male survivors and their female partners who did not sustain CSA. In most studies, CSA criteria referred to sexual acts involving contact with the victim. Articles also included offender's characteristics (i.e., identity, age difference with the victim), while only one of them included information on frequency and duration of CSA. Two studies did not define the CSA criteria considered. Both studies conducted by Kia-Keating and colleagues $(2005,2010)$ are based on the same sample but since their results provide additional insights into the data, they were both considered. Two main approaches to data analysis were used, grounded theory and phenomenology.

Study quality was assessed using the checklist of Kmet et al. (2004) for quality scoring of qualitative studies included in this metasynthesis. Ten components were assessed (e.g., verification of procedures, reflexivity of the account). Scores were summed and calculated as a percentage, ranging from 0 to $100 \%$, by two independent researchers. Thereafter, disparities between scores were discussed until a consensus was reached. Description and justification of each component were attributed a score of 0 (no), 1 (partial) or 2 (yes) and calculated as a percentage. All of the qualitative studies scored $80 \%$ or higher, which attests to their quality.

Table 1. Studies included in metasynthesis

\begin{tabular}{|c|c|c|c|c|c|c|c|}
\hline \# & Authors & Year & $\begin{array}{l}\text { Research } \\
\text { design }\end{array}$ & Qualitative sample & CSA Criteria & $\begin{array}{c}\text { Approach to data } \\
\text { analysis }\end{array}$ & $\begin{array}{l}\text { Quality } \\
\text { score }\end{array}$ \\
\hline 1 & $\begin{array}{l}\text { Newsom \& } \\
\text { Myers- } \\
\text { Bowman }\end{array}$ & 2017 & $\begin{array}{l}\text { Qualitative; } \\
\text { Open-ended } \\
\text { interview }\end{array}$ & $\begin{array}{l}6 \text { women; Living in USA, } \\
\text { White Americans, } \\
\text { Between } 18 \text { and } 55 \text { years } \\
\text { of age }(m=40)\end{array}$ & $\begin{array}{l}\text { CSA occurred } 5 \text { times or } \\
\text { more over a minimum of a } \\
\text { 1-year period }\end{array}$ & $\begin{array}{l}\text { Inductive; } \\
\text { Symbolic interactionist; } \\
\text { Phenomenology }\end{array}$ & $80 \%$ \\
\hline 2 & $\begin{array}{l}\text { Hitter, } \\
\text { Adams \& } \\
\text { Cahill }\end{array}$ & 2017 & $\begin{array}{l}\text { Qualitative; } \\
\text { Semi-structured } \\
\text { interview; } \\
\text { Researcher's self- } \\
\text { reflexive journal }\end{array}$ & $\begin{array}{l}\mathbf{8} \text { women; Living in USA, } \\
1 \text { Latina, } 6 \text { non-Latina } \\
\text { white \& } 1 \text { multi-ethnic, } \\
\text { Between } 28 \text { and } 45 \text { years } \\
\text { of age }\end{array}$ & $\begin{array}{l}\text { CSA defined as any sort of } \\
\text { sexual contact and exposure } \\
\text { to pornography before age } \\
15 \text { with someone at least } \\
5 \text { years older than the child }\end{array}$ & Thematic analysis & $85 \%$ \\
\hline $\begin{array}{l}3 \\
4\end{array}$ & $\begin{array}{l}\text { Kia-Keating, } \\
\text { Grossman, } \\
\text { Sorsoli, \& } \\
\text { Epstein } \\
\text { Kia-Keating, } \\
\text { Sorsoli \& } \\
\text { Grossman }\end{array}$ & 2005 & $\begin{array}{l}\text { Qualitative; } \\
\text { Semi-structured } \\
\text { interviews }\end{array}$ & $\begin{array}{l}16 \text { men; Living in USA, } \\
\text { Multi-ethnic, } 41.5 \text { years } \\
\text { old average }\end{array}$ & $\begin{array}{l}\text { Severe CSA, defined as } \\
\text { incestuous abuse and/or } \\
\text { abuse by a caretaker } \\
\text { (teacher, babysitter, etc.) } \\
\text { involving oral, anal, or } \\
\text { genital intercourse or } \\
\text { attempted intercourse }\end{array}$ & Grounded theory & $90 \%$ \\
\hline 5 & $\begin{array}{l}\text { Singh, } \\
\text { Garnett, \& } \\
\text { Williams }\end{array}$ & 2013 & $\begin{array}{l}\text { Qualitative; } \\
\text { Semi-structured } \\
\text { interviews }\end{array}$ & $\begin{array}{l}10 \text { women; Living in } \\
\text { USA, African American, } \\
\text { Above } 18 \text { years-old }\end{array}$ & $\begin{array}{l}\text { CSA occurred before } 12 \\
\text { years old }\end{array}$ & $\begin{array}{l}\text { Phenomenology; } \\
\text { Feminism } \\
\text { empowerment theory; } \\
\text { African feminist theory }\end{array}$ & $85 \%$ \\
\hline 6 & $\begin{array}{l}\text { Crete \& } \\
\text { Singh }\end{array}$ & 2015 & $\begin{array}{l}\text { Qualitative; } \\
\text { Semi-structured } \\
\text { individual and } \\
\text { couple } \\
\text { interviews }\end{array}$ & $\begin{array}{l}\mathbf{5} \text { men and their female } \\
\text { partners; Living in USA, } \\
\text { White, Between 20-60 } \\
\text { years of age }\end{array}$ & Undefined & $\begin{array}{l}\text { Phenomenology; } \\
\text { Grounded in relational- } \\
\text { cultural theory (RCT) }\end{array}$ & $80 \%$ \\
\hline 7 & $\begin{array}{l}\text { Hartley, } \\
\text { Johnco, } \\
\text { Hofmeyr, \& } \\
\text { Berry }\end{array}$ & 2016 & $\begin{array}{l}\text { Qualitative } \\
\text { Semi-structured } \\
\text { interviews }\end{array}$ & $\begin{array}{l}6 \text { women; Living in UK, } \\
3 \text { British \& } 3 \text { Indian, } \\
\text { Between } 30-52 \text { years of } \\
\text { age }\end{array}$ & $\begin{array}{l}\text { CSA occurred before } 16 \text { and } \\
\text { perpetrated by a family } \\
\text { member. CSA defined as } \\
\text { sexual acts by an adult } \\
\text { above } 18 \text { years-old or } \\
5 \text { years-old older than the } \\
\text { victim }\end{array}$ & Phenomenology & $90 \%$ \\
\hline 8 & $\begin{array}{l}\text { Roller, } \\
\text { Martsolf, } \\
\text { Draucker \& } \\
\text { Ross }\end{array}$ & 2009 & $\begin{array}{l}\text { Qualitative; } \\
\text { Semi-structured } \\
\text { interviews }\end{array}$ & $\begin{array}{l}\mathbf{4 7} \text { men and } 48 \\
\text { women; Living in UK, } \\
\text { Multi-ethnic, Between } 18 \\
\text { and } 62 \text { years of age }\end{array}$ & Undefined & $\begin{array}{l}\text { Grounded theory; } \\
\text { Constant comparison } \\
\text { analysis }\end{array}$ & $80 \%$ \\
\hline
\end{tabular}




\footnotetext{
"A journey back to my wholeness": A qualitative metasynthesis on the relational and sexual recovery process of child sexual abuse survivors
}

\section{Analytic strategy}

The question that guided analysis in this study was the following: how do CSA survivors recover from relational and sexual issues left by CSA experiences? To answer this question, a direct content analysis (Hiesh \& Shannon, 2005) was conducted in light of The Drive to Move Forward Framework (Ochocka et al., 2005). This framework is based on findings from a longitudinal qualitative study among individuals affected by serious mental illnesses and other life events involving struggle, with a focus on the recovery process of these individuals. This process is non-linear, including both successes (i.e., positive changes) and setbacks (i.e., negative changes) and is ecologically oriented (i.e., experienced within the context of personal and external circumstances). The first concept of the recovery process is the "drive to move forward", characterized by internal forces and a motivation to move forward and overcome current struggles. The drive to move forward is mainly manifested by awakenings or changes in perceptions or attitudes (e.g., hope, optimism). Another concept of the framework relies on accommodation-oriented strategies (e.g., knowing one's illness, acceptance of limits and capacities) and action-oriented strategies (e.g., taking control, seeking support) that individuals can deploy. These strategies can be cognitive, behavioral or both. The strategies are seen as mechanisms of life change (i.e., positive or negative), which will further add to life experiences. Finally, "circumstances that may influence the process of recovery" such as internal and external circumstances constitute the last component. Internal-related components refer to personal characteristics (e.g., emotions, attitudes), while external-related components refer to social or environmental characteristics (e.g., stigma, responsive services) that may facilitate or hinder recovery. CSA and its consequences on intimacy and sexuality can be seen as a life struggle and encompass many mutual components of the recovery process. Studies about recovery and resilience in CSA survivors identified major turning points or awakenings, as well as adaptive coping strategies that can be used to move forward from the abuse (Chouliara et al., 2014; Easton et al., 2015). It is thereby arguable that this framework can apply to other forms of adversity, such as CSA.

As a first step in analysis, a coding procedure (i.e., assigning codes to each narrative excerpt) was performed using an open coding grid based on the framework, but which could also be improved according to data. Afterward, conceptual categories (i.e., a brief analytical description that best describes the general orientation of a code set; Paillé, 1994) were created where segments of the narratives were classified according to each concept of the framework (Hiesh \& Shannon, 2005). Data that did not fit with the framework (e.g., narratives related to "reclaiming sexuality") were still considered to form new categories as a part of the recovery process. For instance, the category "The drive to move forward after CSA: a prerequisite to relational and sexual recovery" is clearly named as the "Drive to Move Forward" concept of the framework but its sub-categories (i.e., It did happen to me and it was wrong, It was not my fault, I forgave myself) are closer to the survivors' discourse. Analysis procedures were supported by Nvivo 12 pro software (QSR international Pty Ltd, 2018).

\section{Research team}

The research team made efforts to be aware of their influence on the findings by a process of reflexivity. Reflexivity refers to general introspection of the role of subjectivity by questioning the changes brought about by researchers as a result of the research process in addition to how these changes may affect the research process in return (Palaganas et al., 2017). Researchers should question themselves about their personal values, assumptions, standpoints, socio-cultural backgrounds, and how these may affect the research design or the findings (Hesse-Biber, 2007). The first and second authors are two women researchers who stem from the discipline of sexology and who are well trained on sexual victimization issues, having several years of expertise and experiences with qualitative methods. The third author, a woman clinical psychologist who is also a researcher in sexology, has several years of clinical expertise with CSA survivors and specialises in marital and sexual problems. Authors of this paper consider survivors as agentive actors of their life and share a positive approach to sexuality. Thus, the authors have a situated standpoint on the topic of this study, which has oriented the research method employed and the data analysis process.

\section{Results}

\section{The relational and sexual recovery process of CSA survivors}

This metasynthesis shows that recovering from CSA and the perceived consequences it can generate within intimate relationships and sexuality is a complex dynamic process for survivors. Results of the analysis uncovered three main categories related to the relational and sexual recovery process of CSA survivors, which are in concordance with The Drive to Move Forward Framework (Ochocka et al., 2005): 1) The drive to move forward after CSA: a prerequisite to relational and sexual recovery; 2) Positive strategies mobilized to recover from relational and sexual issues left by CSA: 


\section{"A journey back to my wholeness": A qualitative metasynthesis on the relational and sexual recovery process of child sexual abuse survivors}

cognitive and behavioral changes to achieve a satisfying intimate and sexual life; and 3) Social circumstances that facilitate or hinder the relational and sexual recovery process. Conceptual categories, subcategories and the studies associated to each sub-category are presented in Table 2 and described in the following section.

Table 2. Categories, sub-categories and studies associated with each sub-category

\begin{tabular}{|c|c|c|}
\hline Categories & Sub-Categories & Studies \# \\
\hline \multirow{2}{*}{$\begin{array}{l}\text { 1. The drive to move forward after } \\
\text { CSA: A prerequisite to relational and } \\
\text { sexual recovery }\end{array}$} & 1.1 CSA awakenings: Recognition of the trauma and exculpation & $1,2,3,4,5,6,7,8$ \\
\hline & 1.2 Hope and determination: A self-definition over and above CSA & $1,6,8$ \\
\hline \multirow{5}{*}{$\begin{array}{l}\text { 2. Positive strategies mobilized to } \\
\text { recover from relational and sexual } \\
\text { issues left by CSA: Cognitive and } \\
\text { behavioural changes to achieve a } \\
\text { satisfying intimate and sexual life }\end{array}$} & $\begin{array}{l}\text { 2.1 Knowing one's own challenges: Figuring out the consequences of CSA on } \\
\text { intimate relationships and sexuality }\end{array}$ & $1,2,3,4,5,6,7,8$ \\
\hline & $\begin{array}{l}\text { 2.2 Recognizing and accepting one's own limits: Setting boundaries in } \\
\text { intimate relationships }\end{array}$ & $1,2,3,4,6,8$ \\
\hline & 2.3 Reclaiming sexuality: Redefining sexuality to better assert it & $1,2,3,4,5,6,7,8$ \\
\hline & $\begin{array}{l}\text { 2.4 Seeking support from therapy: Learning about and voicing intimacy and } \\
\text { sexuality within a safe space }\end{array}$ & $2,4,5$ \\
\hline & $\begin{array}{l}\text { 2.5 Engaging in a supportive community: Giving back to others to help } \\
\text { oneself recover }\end{array}$ & 2 \\
\hline \multirow{2}{*}{$\begin{array}{l}\text { 3. Social circumstances that } \\
\text { facilitate or hinder the relational } \\
\text { and sexual recovery process }\end{array}$} & 3.1 Facilitator to recovery: Caring intimate relationships & $1,2,3,4,6,7$ \\
\hline & $\begin{array}{l}\text { 3.2 Hindrances to recovery: Traditional gender standards and social } \\
\text { oppression }\end{array}$ & $3,4,5,6$ \\
\hline
\end{tabular}

Note. The Studies \# column refers to the numbers assigned in Table 1.

\section{The drive to move forward after CSA: A prerequisite to relational and sexual recovery}

Narratives of male and female survivors across studies show that despite the struggles they face regarding CSA, they have found internal strengths or sources of motivation that have led them to move forward from these negative experiences. They reported several awakenings related to experienced CSA as well as hope and determination to overcome these experiences, which seem to be prerequisites for tackling their relational and sexual difficulties.

1.1 CSA awakenings: Recognition of the trauma and exculpation. As a protection mechanism or because they were too young to understand, many survivors have addressed a period of their life where they were partially or completely unaware that they experienced CSA. Results suggest that to move forward and overcome relational and sexual difficulties, survivors had to recognize these experiences as a CSA, recognize its severity or impacts, and put the responsibility back on their aggressor.

It did happen to me and it was wrong. Several male and female participants across studies mentioned that recognition of the sustained experience as CSA was a turning point in their process of recovery: "Now I'm ready to just try to get it open, open up, just say it, because it did occur" (Anthony, cited in Kia-Keating et al., 2005). For many survivors, the awakening of CSA was triggered by a first exposure to intimacy and sexuality, leading them to realize that these experiences were wrong: "I was in seventh grade in school because they started teaching at that time, they started ... in health, about the body and stuff. And I was in seventh grade when I started to realize these things were wrong" (49year-old woman, cited in Roller et al., 2009).

It was not my fault. Survivors in different studies reported the experience of shame and culpability following CSA. In their process of recovery, they stated that shifting the blame and responsibility toward the aggressor appeared to be a form of self-release and helped them to move on: "Later, I realized this wasn't about me-it was about my abuser - and that made a huge difference in my life" (Rayna, cited in Singh et al., 2013).

I forgave myself. In connection with the need to move the responsibility towards their aggressor, some survivors realized that they did not consent to these experiences as a child and have forgiven themselves for having "participated" in the abuse or for the way they reacted: "[lt was] hard to forgive myself, but it's a non-issue now, because I have forgiven myself... An honest look at the impact of the experience, placing blame and responsibility where it belongs, physiological response does not indicate consent" (Beth, cited in Newsom \& Myers-Bowman, 2017). 


\footnotetext{
"A journey back to my wholeness": A qualitative metasynthesis on the relational and sexual recovery process of child sexual abuse survivors
}

1.2 Hope and determination: A self-definition over and above CSA. Some survivors touch upon hope and determination as strong wills to change things and to live their lives with empowerment. For example, a female participant expressed determination to not define herself through the CSA situations she experienced:

"You become resilient when you are able to have strength and support, to where you go, 'It's not gonna bother me...' You become resilient when you can let it go or when you make the decision that it's not going to define you" (Martina, cited in Newsom \& Myers-Bowman, 2017).

\section{Positive strategies mobilized to recover from relational and sexual issues left by CSA: Cognitive and behavioural changes to achieve a satisfying intimate and sexual life}

All participants across studies addressed several consequences of CSA within their relational and sexual lives. Difficulties mentioned by men were more focused on relational abilities and sexual orientation confusion while women's difficulties were rather related to sexuality. In order to cope with these consequences, participants evoked various positive strategies that can relate to cognitive and behavioural changes. Men's strategies focused on a renegotiation of their intimate relationships by setting their boundaries and challenging masculinity standards, while women reported strategies focused on reclaiming their sexuality and asserting sexual needs.

2.1 Knowing one's own challenges: Figuring out the consequences of CSA on intimate relationships and sexuality. All participants across studies mentioned that they had to figure out the consequences of CSA within their intimate and sexual life as a part of their recovery process. Many survivors across studies mentioned that CSA has led them to be distrustful with others in addition to having difficulties in establishing close relationships. Several participants also mentioned that sexuality was painful and unpleasant, filled with a sense of guilt and shame. Men participants had a tendency to build a protective wall around them to avoid reliving vivid painful emotions. They also reported difficulties in being touched, communicating with their romantic partners, accepting love and care, a confusion in their gender identity or sexual orientation, as well as avoidant or compulsive sexual behaviours. Women evoked sexual self-objectification and a disinhibited sexuality involving multiple casual partners as part of the consequences of CSA. A woman also reported the explicit expectation that her romantic partners would inevitably be violent or abusive with her. Thereby, as illustrated by a man's narrative, the consequences of such experiences may have led survivors to use protection strategies in order to survive:

"All of the trusted figures around me either vanished or abused me in some way, and I can't trust them and therefore I got to do this myself, so pulling in and building walls, building a shell, a protective shell. So that protective shell has been very important... It's part of how I survived" (Martin, cited in Kia-Keating et al., 2010).

Participants reported that figuring out the consequences of CSA on their intimate relationships and sexuality prompted them to overcome their difficulties and adjust their vision as well as their behaviours in their relational and sexual lives. Thereby, the recognition of these consequences served as a starting point to make personal changes within their relational and sexual lives: "I just reached a point where I said I am sick of living, being promiscuous, being a pushover. At that point, I found my strength" (40-year-old woman, cited in Roller et al., 2009). The desire to make personal changes within their relational and sexual lives was also manifested by a need to more deeply understand the consequences. For example, a participant characterized the consequences of CSA experiences as "a mess... a cycle that becomes overwhelming", which led him to do "intense analysis" in order to tackle his abuse (54-year old men, cited in Roller et al., 2009).

2.2 Recognizing and accepting one's own limits: Setting boundaries in intimate relationships. Male participants across studies asserted that they were able to recognize and accept their personal limits within their intimate and sexual relationships, which were mostly related to their difficulty with proximity and mistrust. A man reported that setting boundaries with women contributed to a greater sense of well-being:

"Say no to a woman as an adult. I mean I've gotten better with that; now I can set boundaries and stuff like that... Now there's a lot of things I can talk about or do that most men can't do, and that tends to work out pretty well. And part of it is being able to say my boundaries and what I need. As long as a woman can handle those things, we're ok" (Brad, cited in Kia-Keating et al., 2005). 
"A journey back to my wholeness": A qualitative metasynthesis on the relational and sexual recovery process of child sexual abuse survivors

2.3 Reclaiming sexuality: Redefining sexuality to better assert it. In order to achieve a more satisfying relational and sexual life, several survivors, which are mostly women, named that they had to reclaim their sexuality by adjusting their sexual thinking, attitudes, and behaviours. These changes ranged from acceptation to affirmation.

Accepting and legitimizing the sexual-self. Several female participants across studies addressed issues related to self-acceptance as a sexual being and the learnings they had made over time. A female participant showed how sexuality became a part of her identity: "I see myself as a whole person and I see my sexuality as part of who I am" (Pam, cited in Singh et al., 2013). Several women across studies also stated that they had to give themselves permission to experiment pleasurable sexual activities to overcome the effects of CSA. As mentioned by a woman, this acceptance of her sexual-self led her to change her perceptions toward sexuality: "Seeing [my]self as more than an object and/or a sexual victim. Acceptance of [my]self as a sexual being, not just a sliced-off part of me that was taken, being able to see things in a new filter" (Jessie, cited in Newsom \& Myers-Bowman, 2017).

Reframing sexuality. Male and female participants across studies shared that they had to adjust their perspective regarding intimacy and sexuality in order to cope with the challenges they were facing. For many female participants in the study of Newsom \& Myers-Bowman (2017), sexuality was no longer perceived as something painful, unwanted or unhealthy: "Sex is desirable in romantic relationships. It is healthy for the most part" (Lucie, cited in Newsom \& Myers-Bowman, 2017). This reconceptualization of sexuality led them to adjust their sexual self-perception: "Once my mentality changed, my sexual image [of me] changed" (Anna, cited in Newsom \& Myers-Bowman, 2017). Several men across studies evoked that they had to redefine masculinity and their perception of manhood in order to improve their sexual well-being. A participant explained how male sexual standards can be challenged by adopting norms considered to be typically feminine: "The actual physicality of sexuality was irrelevant. Everything, the entire experience was totally on the context. It was very, in our society, a very non-male way of looking at sexuality. What experiences were best ... that I like the person, that I feel safe, you know, like, trust, cute, cuddly, sweet" (Morgan, cited in Kia-Keating et al., 2010).

Connecting to one's own intimate and sexual needs and desires. Female survivors across studies recognized the importance of connecting to their needs and desires within their intimate relationships and sexuality. A woman from the study of Roller et al., (2009) explained the switch she had made regarding her perceptions about sexuality during introspection: "I would stay [in relationships] because I wanted to please them [men]. Now I don't worry so much about pleasing them, I'm worried about how I feel... I worry about if it is good for me". As stated by another woman, connecting to oneself also means there is no longer the strict need to please intimate partners to stay authentic:

"I always saw myself as an adjunct to someone else before, especially my father and it was very necessary to please him... I kind of carried that into adult life... dealing with the trauma has made other people irrelevant in the sense that I don't need to be a part of them, they can either accept me or reject me for who I am" (Kate, cited in Hartley et al., 2016).

Asserting and negotiating intimate and sexual needs. Several women and a few men across studies state that despite the sexual difficulties they endured, they now tend to express more openly about their intimate and sexual needs or desires, as well as being better able to negotiate sexuality with their partners. A male participant reflected upon the way he was able to express his personal limits within his relationships:

"I still have an issue about intimacy. I'm intimate, but then again sometimes, I have my bad days where I don't want to be touched... And I let them know it is not you, it has nothing to do with you. I'm just in one of those... I just don't want to be touched today" (Alejandro cited from Kia-keating et al., 2005).

Assertiveness in intimate relationships emerged in the survivors' discourse as a key aspect fostering selfconfidence. To demonstrate this point, a woman survivor expressed the fact that she no longer felt vulnerable in presence of men, which had led her to become more assertive:

"I have always been really scared of male attention or male kind of anything... it was kind of 'oh my God it's a boy'... I guess I felt very vulnerable, whereas I don't feel vulnerable now, I feel more... confident within myself, I'm more assertive (Parul, cited in Hartley et al., 2016). 


\footnotetext{
"A journey back to my wholeness": A qualitative metasynthesis on the relational and sexual recovery process of child sexual abuse survivors
}

2.4 Seeking support from therapy: Learning about and voicing intimacy and sexuality within a safe space. Men and women across studies indicated that they sought support from a professional in order to tackle the challenges they faced especially within their intimate life. Some women across studies evoked that they found it useful to consult a therapist to address their sexual issues. As reported by some men, therapy constituted a safe space to address trust issues. One male participant explained how the bond he developed with his therapist contributed to heal his broken trust:

"Trust is a miracle. I've never trusted anybody. And it's the biggest single by-product of my therapy, just learning that I can sit in a room with another person and they don't have any desire to abuse me. It's a big deal" (Bill, cited in Kia-Keating et al., 2010).

2.5 Engaging in a supportive community: Giving back to others to help oneself recover. After finding strategies to overcome their own relational and sexual difficulties, some survivors engaged in a supportive community to provide guidance to other trauma survivors. A woman stated that she is committed to make a difference and help other women that are still struggling with sexual difficulties:

"I feel like my sexual power has come from being able to claim it for myself and simultaneously offer it to others. To be able to root myself in this community of women who say, 'sex is positive, desire is positive.' As long as it is healthy for you, feels consensual, and you are able to openly communicate your desires in whatever ways... then the world is wide open in terms of sex and sexuality... It meant being able to own who I really was and do that in a context without shame. Now I give other women the same opportunity" (Nina, cited in Hitter et al., 2017).

The process of helping others also played a role in the recovery process, as illustrated in the following man's narrative: "It will help me to reclaim my own body and help me to teach other people to reclaim theirs" (Bill, cited in Kia-Keating et al., 2010).

\section{Social circumstances that facilitate or hinder the relational and sexual recovery process}

Positive intimate relationships were reported as a key factor promoting the relational and sexual recovery process of several men and women across studies. Survivors explained that they had to cope with stereotypical gender norms and social oppression present within society, which may hinder their relational and sexual recovery process. Thus, their recovery process illustrates a duality between their determination to overcome relational and sexual issues related to past CSA experiences and the social circumstances that may modulate this process.

3.1 Facilitator to recovery: Caring intimate relationships. Many female and male survivors across studies reported positive and caring intimate relationships as a central aspect fostering their recovery process. A woman expressed how the support from her romantic partner allowed her to feel more empowered: "I felt empowered in my relationship. He [her boyfriend] gave me the freedom to use my voice and respected and valued it" (Suzy, cited in Newsom \& Myers-Bowman, 2017). Survivors also described how healthy and trustworthy intimate relationships promoted a place for safety, love, and acceptation, while those same feelings were violated during the abuse. Being surrounded by an intimate partner who believes in them, who is loving and caring, was reported as fostering healing by a male survivor: "I feel that having someone who loves me, believes in me, is willing to fight for me, who sees me as heroic, who sees me as a gifted and wonderful person is extremely affirming... that is a healing presence" (Doug, cited in Crete \& Singh, 2015). Since many survivors experienced a fear of being blamed or not being believed, it was more difficult for them to disclose CSA experiences to their partners. Yet, the context of a caring intimate relationship seemed to facilitate disclosures and turned them into a positive experience:

"When I disclosed to him, I thought he'd blame me, but one major relief to me was that he didn't ... I thought 'oh my God he's not blaming me, maybe it's not my fault', very confusing, one of the things was that he was totally understanding towards me" (Carla, cited in Hartley et al., 2016).

3.2 Hindrances to recovery: Traditional gender standards and social oppression. The discourse of some survivors across studies highlighted that traditional gender standards can hinder their process of relational and sexual recovery. As expressed by one woman, when they do not correspond to femininity standards, it can impair their body image:

"I still struggle... I live in a culture where I am the antithesis of what a woman is supposed to be. I'm a fat dyke. I've been fat pretty much my whole life. For a long time, I was totally ashamed of my body, 


\footnotetext{
"A journey back to my wholeness": A qualitative metasynthesis on the relational

and sexual recovery process of child sexual abuse survivors
}

and of what my body looks like, because it didn't look like what it's supposed to look like. To unlearn that has been one of the most difficult things for me outside of the sexual abuse" (Nina, cited in Hitter et al., 2017).

Analysis of men's narratives shows that traditional standards of masculinity tend to affect their relational and sexual recovery process because of the feeling of stigma they can induce. A male participant voiced how men that are struggling with their sexuality, as a result of the CSA, must also cope with the shame associated with not conforming to valued masculine standards: "We [men] have an extra layer of shame and everything else because after all, we're supposed to enjoy [sexual intimacy]... and we're supposed to be strong enough to be able to just like fight it off or something" (Bill, cited in Kia-Keating et al., 2005).

Hindrances in the relational and sexual recovery process of female survivors were mostly expressed by African American women in the study of Singh et al., (2013). They discussed an intersection of stigmatizing experiences, being a Black woman and having experienced CSA, which have impacted their sexuality. One woman underscored social oppression, such as being treated disrespectfully and unequally regarding sexuality by her entourage at a younger age. As this woman attests, even if social oppression seemed to affect their process of recovery, they became more aware of themselves as a sexual being, which promoted their resilience:

"Just as a young Black girl there are lots of messages anyway about sex and sexuality. Both I think from the outside that even as a young child I remember being very sexualized. Even teachers in school would make comments about my breasts as they were developing or how shapely I was. I probably developed quickly. Just adults, or even just random people would comment, even touch me. I don't think necessarily sexually but in ways that made me very aware of myself as a sexual being, which I tend to think happens more to women of color" (Simone, cited in Singh et al., 2013).

\section{Discussion}

This metasynthesis portrays the complex relational and sexual recovery process of CSA survivors. Results highlight that survivors will go through different stages of recovery from CSA experiences and their relational and sexual impacts. These stages can occur simultaneously or at different periods of their life, following a progression from the drive to move forward to the mobilization to use strategies to recover and the social circumstances surrounding recovery. Also, the process may involve stepping backwards (e.g., survivors may develop strategies to deal with their sexual and relational difficulties, but may still find it difficult to implement and maintain these strategies over time, which leads them to relive those difficulties).

More precisely, participants evoked a need to address and make sense of the experienced CSA (i.e., CSA Awakenings), along with the hope and self-determination to get over these painful experiences. These turning points emerged as pivotal to recover from relational and sexual difficulties and may serve as prerequisites to psychological and behavioural changes. Then, recovery strategies such as self-knowledge, acceptance, affirmation, and connection to one's sexuality were reported as offering a precious basis from which CSA survivors may renegotiate intimacy and sexuality within themselves and in interpersonal contexts. Seeking support from help providers, such as a therapist, also appears to be an important strategy promoting a sense of security. The therapeutic context may also constitute an opportunity for survivors to voice and make sense of their mental states and interpersonal world (i.e., mentalization), which in turn promotes sexual and relational functioning (Maclntosh et al., 2019). Finally, creating a healthy and supportive relationship with an intimate partner and giving back to people with whom they shared common experiences creates a sense of safety, belonging, and accomplishment in survivors and enables the development of a supportive network, which in turn contributes to their own recovery process (Kia-Keating et al., 2010). Indeed, positive relationships that involve support and emotional depth can provide a space to explore healthy relational dynamics and a protective effect associated with more adaptive functioning in CSA survivors (Afifi \& MacMillan, 2011; Trickett et al., 2011). For many survivors, CSA disclosure occurs unintentionally in the context of sexual relationships with their partners, often prompted by flashbacks and dysfunctions. Yet, as reported by Maclntosh et al., (2016), the partner's positive responses to disclosure promote recovery (e.g., decreasing feelings of shame), while negative responses hamper it (e.g., increasing feelings of shame, negatively impacting help-seeking). Overall, support from the intimate partner, but also from friends, family members, survivor groups or therapists is essential for building strong relationships and for recovering (Howard Sharp et al., 2017). However, some social contexts may hinder the recovery process, including those leading to stigma and oppression. Results showed that being a survivor of CSA as well as thinking and 


\footnotetext{
"A journey back to my wholeness": A qualitative metasynthesis on the relational

and sexual recovery process of child sexual abuse survivors
}

behaving outside the norms of hegemonic masculinity may induce an extra layer of shame in male survivors (e.g., negative feelings, gender role conflicts; Alaggia \& Millington, 2008; Easton, 2014), which also constitute barriers to disclosure and help-seeking (Alaggia et al., 2019). Additional stigma can also be induced by experiencing different forms of oppressions, such as sexism and racism among African American women (Singh et al., 2013). Thus, for both male and female survivors, stigma appears to be intimately related to social circumstances and conflict with the prevailing norms. Finally, the narratives of men show that their challenges and coping strategies are mainly related to relational difficulties, while women's discourses were more focused on sexual difficulties and empowerment, indicating potential gender specificities in their relational and sexual recovery process.

\section{Strengths and limitations}

This metasynthesis enriches the actual body of knowledge by identifying key aspects of the process of recovering from CSA and its consequences on intimate relationships and sexuality. An important contribution of this metasynthesis is that it allows for the substantiation and conceptual extension of The Drive to Move Forward Framework (Ochocka et al., 2005). The recovery process identified in this study highlights the hierarchical but iterative nature of the framework's components and suggests the importance of considering coping strategies that are specific to relational and sexual difficulties. This metasynthesis meets scientific criteria of qualitative studies in many ways, which reinforce the credibility of the findings (Noble \& Smith, 2015). For instance, the researchers' reflexivity on personal bias has been described, trustworthiness was fostered by inter-rater reliability, a detailed description of the data analysis as well as repeated meetings with other researchers ensured a common understanding of the results, and the use of a conceptual framework taking the previous work on the subject into account while allowing new discoveries promoted the credibility of the findings.

Results of this metasynthesis should also be appreciated while taking into account its limitations. Firstly, a directed analysis based on a conceptual framework tends to suppress interpretive creativity and may reduce some of the vividness of insight seen in qualitative research; researchers may not consider the data that does not fit within the framework (Dixon-Woods, 2011). However, the hybrid approach used in this metasynthesis (i.e., using a conceptual framework to analyze the data and integrating data and potential categories that did not fit the framework; Elo \& Kyngäs, 2008) may temper this limit. Secondly, data saturation (i.e., when the data collected no longer provide new insights on a topic, which leads researchers to cease data collection; Faulkner \& Trotter, 2017) could not be achieved for all conceptual categories, as this metasynthesis relied on topics covered in published studies. Likewise, some conceptual categories or subcategories were addressed primarily by women (e.g., reclaiming sexuality), while others were approached rather by men (e.g., accepting one's own limits). However, further study is needed, especially on male survivors, to better understand gender specificities. Thirdly, few studies have documented social factors involved in the recovery process of CSA survivors, suggesting the need to investigate them in more depth. Fourthly, selected articles were conducted in Western Countries, which probably obscures the experiences of participants from different ethnic backgrounds and environments.

\section{Implications for practice}

Several recommendations for practice can be proposed. Firstly, since relational and sexual difficulties are likely to emerge in adolescence who have sustained sexual victimization (Byers et al., 2019), it is important to provide welltailored interventions from an early age. Upstream interventions could prevent the crystallization of relational and sexual difficulties among survivors. Providers working with adult CSA survivors should provide a personalized approach that respects their process of relational and sexual recovery. Tailored-interventions may provide self-reflective activities regarding intimacy and sexuality, as well as behavioral-oriented activities promoting empowerment and assertiveness. In addition to fostering relational and sexual well-being in survivors, strengthening their sexual assertiveness could help reduce revictimization risks (Livingston et al., 2007). Secondly, since CSA often occurs in the context of attachment relationships, recovery may be fostered in the context of positive romantic relationships. Romantic partners are often privileged confidants or allies for survivors, and for that reason they should be included in the therapeutic process. Partners could be informed about the consequences of trauma and possible strategies to optimize the intimate relationship and sexuality (Berthelot et al., 2014; Maclntosh et al., 2016). Thirdly, relational and sexual recovery is a complex process that must be assessed and borne according to an ecological approach. CSA survivors can undergo other traumas and oppressions (e.g., racism, sexism) and thereby experience social stigma, which can exacerbate their relational and sexual difficulties. Providers working with this population would benefit from adopting an intersectional approach as well as a social justice perspective that would grasp the impacts of multiple oppressions on the survivors' 
recovery process (Singh et al., 2013). Fourthly, men and women present common relational and sexual issues related to CSA experiences, but are also subject to gender-based sexual standards. In this regard, they are likely to experience distinct outcomes and healing strategies (Graves et al., 2017). Men's recovery process seem to be facilitated when therapists promote survivors' gender self-acceptance and encouraging them to reflect on cultural representations of men in modern society (Crable et al., 2013; Graves et al., 2017), while promoting sexual agency and empowerment are documented as helpful therapeutic targets among women (Hitter et al., 2017). Thus, therapists should provide gendered tailored-interventions and gender-responsive care to meet the needs of CSA survivors.

\section{Conclusion}

This metasynthesis shows that CSA survivors demonstrate relational and sexual resilience, even if their process of recovery encompasses setbacks. Male and female survivors were found to face gender-specific issues, supporting the relevance of tailored-intervention for this population. Findings also highlight the importance of developing interventions that take into account the social resources of survivors and the social contexts that can facilitate or hinder their recovery process. While there is a need to conduct more studies to deepen our understanding of the mechanisms CSA survivors deploy to face intimacy and sexually related challenges, findings of this metasynthesis are promising and encourage CSA survivors to remain hopeful in the journey back to their wholeness.

\section{Funding}

This research was not supported by a any grant.

\section{Conflict of interest}

The authors declare no potential conflicts of interest with respect to the research, authorship, and/or publication of this article.

\section{Acknowledgements}

The authors wish to thank men and women survivors of child sexual abuse who participated in the studies included in this review.

\section{References}

Aaron, M. (2012). The pathways of problematic sexual behavior: A literature review of factors affecting adult sexual behavior in survivors of childhood sexual abuse. Sexual Addiction \& Compulsivity, 19(3), $199-218$. https://doi.org/10.1080/10720162.2012.690678

Afifi, T. O., \& MacMillan, H. L. (2011). Resilience following child maltreatment: A review of protective factors. Canadian Journal of Psychiatry, 56(5), 266-272. https://doi.org/10.1177/070674371105600505

Alaggia, R., Collin-Vézina, D., \& Lateef, R. (2019). Facilitators and barriers to child sexual abuse (CSA) disclosures: A research update (2000-2016). Trauma, Violence, \& Abuse, 202), 260-283. https://doi.org/10.1177/1524838017697312

Alaggia, R., \& Millington, G. (2008). Male child sexual abuse: A phenomenology of betrayal. Clinical Social Work Journal, 36(3), 265275. https://doi.org/10.1007/s10615-007-0144-y

Arias, B. J., \& Johnson, C. V. (2013). Voices of healing and recovery from childhood sexual abuse. Journal of Child Sexual Abuse, 22(7), 822-841. https://doi.org/10.1080/10538712.2013.830669

Banyard, V. L., \& Williams, L. M. (2007). Women's voices on recovery: A multi-method study of the complexity of recovery from child sexual abuse. Child Abuse \& Neglect, 37(3), 275-290. https://doi.org/10.1016/j.chiabu.2006.02.016

Berthelot, N., Godbout, N., Hébert, M., Goulet, M., \& Bergeron, S. (2014). Prevalence and correlates of childhood sexual abuse in adults consulting for sexual problems. Journal of Sex \& Marital Therapy, 40(5), $434-443$. https://doi.org/10.1080/0092623X.2013.772548

Byers, E. S., O'Sullivan, L. F., \& Hughes, K. (2019). Sexual functioning of late adolescents and young adults in relationships: Association with individual characteristics and relationship factors. Sexual and Relationship Therapy. Advance online publication. https://doi.org/10.1080/14681994.2019.1626982 
"A journey back to my wholeness": A qualitative metasynthesis on the relational and sexual recovery process of child sexual abuse survivors

Calhoun, L. G., Cann, A., \& Tedeschi, R. G. (2010). The posttraumatic growth model: Sociocultural considerations. In T. Weiss \& R. Berger (Eds.), Posttraumatic growth and culturally competent practice: Lessons learned from around the globe (pp. 1-14). John Wiley \& Sons Inc. https://doi.org/10.1002/9781118270028.ch1

Calhoun, L. G., Cann, A., Tedeschi, R. G., \& McMillan, J. (2000). A correlational test of the relationship between posttraumatic growth, religion, and cognitive processing. Journal of Traumatic Stress, 13(3), 521-527. https://doi.org/10.1023/A:1007745627077

Carreiro, A. V., Micelli, L. P., Sousa, M. H., Bahamondes, L. \& Fernandes, A. (2016). Sexual dysfunction risk and quality of life among women with a history of sexual abuse. International Journal of Gynecology \& Obstetrics, 134(3), $260-263$. https://doi.org/10.1016/j.ijgo.2016.01.024

Choate, L. H. (2012). Sexual trauma: An ecological approach to conceptualization and treatment. In L. Lopez Lever (Ed.), Trauma Counseling: Theories and Interventions (pp. 116-131). Springer. https://doi.org/10.1891/9780826106841.0007

Chouliara, Z., Karatzias, T., \& Gullone, A. (2014). Recovering from childhood sexual abuse: A theoretical framework for practice and research. Journal of Psychiatric and Mental Health Nursing, 21(1), 69-78. https://doi.org/10.1111/jpm.12048

Crable, A. R., Underwood, L. A., Parks-Savage, A., \& Maclin, V. (2013). An examination of a gender-specific and trauma-informed training curriculum: implications for providers. International Journal of Behavioral Consultation and Therapy, 7(4), 30-37. https://doi.org/10.1037/h0100964

Crete, G. K., \& Singh, A. A. (2015). Resilience strategies of male survivors of childhood sexual abuse and their female partners: A phenomenological inquiry. Journal of Mental Health Counseling, 37(4), 341-354. https://doi.org/10.17744/mehc.37.4.05

Dixon-Woods, M. (2011). Using framework-based synthesis for conducting reviews of qualitative studies. BMC Medicine, 9(1), 39. https://doi.org/10.1186/1741-7015-9-39

Domhardt, M., Münzer, A., Fegert, J. M., \& Goldbeck, L. (2015). Resilience in survivors of child sexual abuse: A systematic review of the literature. Trauma, Violence, \& Abuse, 16(4), 476-493. https://doi.org/10.1177/1524838014557288

Draucker, C. B., Martsolf, D. S., Roller, C., Knapik, G., Ross, R., \& Stidham, A. W. (2011). Healing from childhood sexual abuse: A theoretical model. Journal of Child Sexual Abuse, 20(4), 435-466. https://doi.org/10.1080/10538712.2011.588188

Draucker, C. B., Martsolf, D. S., Ross, R., Cook, C. B., Stidham, A. W., \& Mweemba, P. (2009). The essence of healing from sexual violence: A qualitative metasynthesis. Research in Nursing \& Health, 32(4), 366-378. https://doi.org/10.1002/nur.20333

Easton, S. D. (2014). Masculine norms, disclosure, and childhood adversities predict long-term mental distress among men with histories of child sexual abuse. Child Abuse \& Neglect, 38(2), 243-251. https://doi.org/10.1016/j.chiabu.2013.08.020

Easton, S. D., Leone-Sheehan, D. M., Sophis, E. J., \&Willis, D. G. (2015). "From that moment on my life changed": Turning points in the healing process for men recovering from child sexual abuse. Journal of Child Sexual Abuse, 24(2), $152-173$. https://doi.org/10.1080/10538712.2015.997413

Elo, S., \& Kyngäs, H. (2008). The qualitative content analysis process. Journal of Advanced Nursing, 62(1), 107-115. https://doi.org/10.1111/j.1365-2648.2007.04569.x

Faulkner, S. L., \& Trotter, S. P. (2017). Data saturation. In J. Matthes, C. S. Davis, \& R. F. Potter (Eds.), The International Encyclopedia of Communication Research Methods (pp. 1-2). Wiley-Blackwell. https://doi.org/10.1002/9781118901731.iecrm0060

Fergusson, D. M., McLeod, G. F., \& Horwood, L. J. (2013). Childhood sexual abuse and adult developmental outcomes: Findings from a 30-year longitudinal study in New Zealand. Child Abuse \& Neglect, 379), 664-674. https://doi.org/10.1016/j.jaac.2013.04.008

Godbout, N., Runtz, M., Maclntosh, H., \& Briere, J. (2013). Childhood trauma and couple relationships. Integrating Science and Practice, 3(2). 14-17.

Graves, E. G., Borders, L. D., \& Ackerman, T. A. (2017). Resilience to child sexual abuse in male college students. Journal of Mental Health Counseling, 39(2), 149-162. https://doi.org/10.17744/mehc.39.2.05

Guyon, R., Fernet, M., Canivet, C., Tardif, M., \& Godbout, N. (2020). Sexual self-concept among men and women child sexual abuse survivors: Emergence of differentiated profiles. Child Abuse \& Neglect, 104, Article 104481. https://doi.org/10.1016/j.chiabu.2020.104481

Guyon, R., Fernet, M., \& Hébert, M. (2019). Relational and sexual experiences of betrayal from the point of view of sexually victimized young women. Journal of Interpersonal Violence. https://doi.org/10.1177/0886260519888197

Hartley, S., Johnco, C., Hofmeyr, M., \& Berry, A. (2016). The nature of posttraumatic growth in adult survivors of child sexual abuse. Journal of Child Sexual Abuse, 25(2), 201-220. https://doi.org/10.1080/10538712.2015.1119773

Hesse-Biber, S. N. (2007). The practice of feminist in-depth interviewing. In S. N. Hesse-Biber, \& P. L. Leavy, Feminist Research Practice (pp. 110-148). SAGE Publications. https://doi.org/10.4135/9781412984270.n5

Hitter, T. L., Adams, E. M., \& Cahill, E. J. (2017). Positive sexual self-schemas of women survivors of childhood sexual abuse. The Counseling Psychologist, 45(2), 266-293. https://doi.org/10.1177/0011000017697194 
"A journey back to my wholeness": A qualitative metasynthesis on the relational and sexual recovery process of child sexual abuse survivors

Homma, Y., Wang, N., Saewyc, E., \& Kishor, N. (2012). The relationship between sexual abuse and risky sexual behavior among adolescent boys: A meta-analysis. Journal of Adolescent Health, 57(1), 18-24. https://doi.org/10.1016/j.jadohealth.2011.12.032

Howard Sharp, K. M., Schwartz, L. E., Barnes, S. E., Jamison, L. E., Miller-Graff, L. E., \& Howell, K. H. (2017). Differential influence of social support in emerging adulthood across sources of support and profiles of interpersonal and non-interpersonal potentially traumatic experiences. Journal of Aggression, Maltreatment \& Trauma, 26(7), $736-755$. https://doi.org/10.1080/10926771.2017.1289999

Hsieh, H. F., \& Shannon, S. E. (2005). Three approaches to qualitative content analysis. Qualitative Health Research, 15(9), $1277-1288$. https://doi.org/10.1177/1049732305276687

Jeong, S., \& Cha, C. (2019). Healing from childhood sexual abuse: A meta-synthesis of qualitative studies. Journal of Child Sexual Abuse, 28(4), 383-399. https://doi.org/10.1080/10538712.2019.1574945

Kendall-Tackett, K. (2012). The long-term health effects of child sexual abuse. In P. Goodyear-Brown (ed.), Handbook of child sexual abuse: Identification, assessment, and treatment (pp. 49-67). John Wiley \& Sons, Inc. https://doi.org/10.1002/9781118094822.ch3

Kia-Keating, M., Grossman, F. K., Sorsoli, L., \& Epstein, M. (2005). Containing and resisting masculinity: Narratives of renegotiation among resilient male survivors of childhood sexual abuse. Psychology of Men \& Masculinity, 6(3), $169-185$. https://doi.org/10.1037/1524-9220.6.3.169

Kia-Keating, M., Sorsoli, L., \& Grossman, F. K. (2010). Relational challenges and recovery processes in male survivors of childhood sexual abuse. Journal of Interpersonal Violence, 25(4), 666-683. https://doi.org/10.1177/0886260509334411

Kmet, L. M., Cook, L. S., \& Lee, R. C. (2004). Standard quality assessment criteria for evaluating primary research papers from a variety of fields. HTA Initiative \#13. Alberta Heritage Foundation for Medical Research. https://doi.org/10.7939/R37M04F16

Kolar, K. (2011). Resilience: Revisiting the concept and its utility for social research. International Journal of Mental Health and Addiction, 9(4), 421. https://doi.org/10.1007/s11469-011-9329-2

Lemieux, S. R., \& Byers, E. S. (2008). The sexual well-being of women who have experienced child sexual abuse. Psychology of Women Quarterly, 32(2), 126-144. https://doi.org/10.1111/j.1471-6402.2008.00418.x

Livingston, J. A., Testa, M., \& VanZile-Tamsen, C. (2007). The reciprocal relationship between sexual victimization and sexual assertiveness. Violence Against Women, 13(3), 298-313. https://doi.org/10.1177/1077801206297339

Maclntosh, H. B., Fletcher, K., \& Ainsworth, L. (2019). Measuring mentalizing in emotionally focused therapy for couples with childhood sexual abuse survivors and their partners. Journal of Couple \& Relationship Therapy, 18(4), $303-329$. https://doi.org/10.1080/15332691.2019.1590274

Maclntosh, H. B., Fletcher, K., \& Collin-Vézina, D. (2016). "I was like damaged, used goods": Thematic analysis of disclosures of childhood sexual abuse to romantic partners. Marriage \& Family Review, 52(6), 598-611. https://doi.org/10.1080/01494929.2016.1157117

Newsom, K., \& Myers-Bowman, K. (2017). "I am not a victim. I am a survivor": Resilience as a journey for female survivors of child sexual abuse. Journal of Child Sexual Abuse, 26(8), 927-947. https://doi.org/10.1080/10538712.2017.1360425

Noble, H., \& Smith, J. (2015). Issues of validity and reliability in qualitative research. Evidence-Based Nursing, 18(2), 34-35. https://doi.org/10.1136/eb-2015-102054

Ochocka, J., Nelson, G., \& Janzen, R. (2005). Moving forward: Negotiating self and external circumstances in recovery. Psychiatric Rehabilitation Journal, 28(4), 315-322. https://doi.org/10.2975/28.2005.315.322

O'Leary, P., Easton, S. D., \& Gould, N. (2017). The effect of child sexual abuse on men: Toward a male sensitive measure. Journal of Interpersonal Violence, 32(3), 423-445. https://doi.org/10.1177/0886260515586362

Paillé, P. (1994). L'analyse par théorisation ancrée. Cahiers de recherche sociologique, (23), 147-181. https://doi.org/10.7202/1002253ar

Palaganas, E. C., Sanchez, M. C., Molintas, M., Visitacion, P., \& Caricativo, R. D. (2017). Reflexivity in qualitative research: A journey of learning. Qualitative Report, 22(2), 426-438. https://nsuworks.nova.edu/tar/vol22/iss2/5

Pereda, N., \& Gallardo-Pujol, D. (2014). One hit makes the difference: The role of polyvictimization in childhood in lifetime revictimization on a southern European sample. Violence and Victims, 29(2), $217-231$. https://doi.org/10.1891/0886-6708.W-D-12-00061R1

QSR International Pty Ltd. (2018) NVivo Qualitative Data Analysis (Version 12) [Software], https://www.qsrinternational.com/nvivoqualitative-data-analysis-software/home

Roller, C., Martsolf, D. S., Draucker, C. B., \& Ross, R. (2009). The sexuality of childhood sexual abuse survivors. International Journal of Sexual Health, 27(1), 49-60. https://doi.org/10.1080/19317610802661870 
Singh, A. A., Garnett, A., \& Williams, D. (2013). Resilience strategies of African American women survivors of child sexual abuse: A qualitative inquiry. The Counseling Psychologist, 41(8), 1093-1124. https://doi.org/10.1177/0011000012469413

Trickett, P. K., Noll, J. G., \& Putnam, F. W. (2011). The impact of sexual abuse on female development: Lessons from a multigenerational, longitudinal research study. Development and Psychopathology, 23(2), 453-476. https://doi.org/10.1017/S0954579411000174

Ungar, M. (2012). Researching and theorizing resilience across cultures and contexts. Preventive Medicine: An International Journal Devoted to Practice and Theory, 55(5), 387-389. https://doi.org/10.1016/j.ypmed.2012.07.021

Vaillancourt-Morel, M. P., Godbout, N., Labadie, C., Runtz, M., Lussier, Y., \& Sabourin, S. (2015). Avoidant and compulsive sexual behaviors in male and female survivors of childhood sexual abuse. Child Abuse \& Neglect, 40, 48-59. https://doi.org/10.1016/j.chiabu.2014.10.024

Wager, N. M. (2013). Sexual revictimization: Double betrayal and the risk associated with dissociative amnesia. Journal of Child Sexual Abuse, 22(7), 878-899. https://doi.org/10.1080/10538712.2013.830666

Walker-Williams, H. J., Van Eeden, C., \& Van der Merwe, K. (2013). Coping behaviour, posttraumatic growth and psychological wellbeing in women with childhood sexual abuse. Journal of Psychology in Africa, 23(2), $259-268$. https://doi.org/10.1080/14330237.2013.10820622 